\title{
Increased Response to $\boldsymbol{\beta}_{2}$-Adrenoreceptor Stimulation Augments Inhibition of $\mathrm{I}_{\mathrm{Kr}}$ in Heart Failure Ventricular Myocytes
}

\author{
Hegui Wang ${ }^{1}$, Yanhong Chen ${ }^{2}$, Hongjun $\mathrm{Zhu}^{2}$, Sen Wang ${ }^{2}$, Xiwen Zhang ${ }^{2}$, Dongjie $\mathrm{Xu}^{2}$, Kejiang Cao ${ }^{2}$, \\ Jiangang Zou ${ }^{2 *}$
}

1 Department of Cardiology, Yijishan Hospital of Wannan Medical College, Wuhu, China, 2 Department of Cardiology, the First Affiliated Hospital, Nanjing Medical University, Nanjing, China

\begin{abstract}
Background: Increasing evidence indicates that the rapid component of delayed rectifier potassium current $\left(I_{\mathrm{Kr}_{\mathrm{r}}}\right)$ is modulated by $\alpha$ - and $\beta$-adrenergic stimulation. However, the role and mechanism regulating $\mathrm{I}_{\mathrm{kr}}$ through $\beta_{2}$-adrenoreceptor $(\beta-A R)$ stimulation in heart failure (HF) are unclear.

Methodology/Principal Findings: In the present study, we investigated the effects of fenoterol, a highly selective $\beta_{2}$-AR agonist, on $\mathrm{I}_{\mathrm{Kr}}$ in left ventricular myocytes obtained from control and guinea pigs with HF induced by descending aortic banding. $I_{\mathrm{Kr}}$ was measured by using whole cell patch clamp technique. In control myocytes, superfusion of fenoterol $(10 \mu \mathrm{M})$ caused a $17 \%$ decrease in $I_{\mathrm{Kr}}$. In HF myocytes, the same concentration of fenoterol produced a significantly greater decrease (33\%) in $\mathrm{I}_{\mathrm{Kr}}$. These effects were not modified by the incubation of myocytes with CGP-20712A, a $\beta_{1}$-AR antagonist, but were abolished by pretreatment of myocytes with ICl-118551, a $\beta_{2}$-AR antagonist. An inhibitory cAMP analog, Rp-cAMPS and PKA inhibitor significantly attenuated fenoterol-induced inhibition of $\mathrm{I}_{\mathrm{Kr}}$ in HF myocytes. Moreover, fenoterol markedly prolonged action potential durations at $90 \%\left(\mathrm{APD}_{90}\right)$ repolarization in $\mathrm{HF}$ ventricular myocytes.
\end{abstract}

Conclusions: The results indicate that inhibition of $\mathrm{I}_{\mathrm{Kr}}$ induced by $\beta_{2}$-AR stimulation is increased in HF. The inhibitory effect is likely to be mediated through a CAMP/PKA pathway in HF ventricular myocytes.

Citation: Wang H, Chen Y, Zhu H, Wang S, Zhang X, et al. (2012) Increased Response to $\beta_{2}$-Adrenoreceptor Stimulation Augments Inhibition of $\mathrm{I}_{\mathrm{Kr}}$ in Heart Failure Ventricular Myocytes. PLoS ONE 7(9): e46186. doi:10.1371/journal.pone.0046186

Editor: Emilio Hirsch, University of Torino, Italy

Received March 21, 2012; Accepted August 28, 2012; Published September 28, 2012

Copyright: (c) 2012 Wang et al. This is an open-access article distributed under the terms of the Creative Commons Attribution License, which permits unrestricted use, distribution, and reproduction in any medium, provided the original author and source are credited.

Funding: This work was supported by the National Nature Science Foundation of China (81170162) http://www.nsfc.gov.cn/Portal0/default166.htm) and University Nature Science Foundation of Jiangsu Province (09KJB320008).The funders had no role in study design, data collection and analysis, decision to publish, or preparation of the manuscript.

Competing Interests: The authors have declared that no competing interests exist.

* E-mail: jgzou@njmu.edu.cn

\section{Introduction}

Heart failure (HF) is associated with significant mortality, with nearly $50 \%$ of deaths occurring suddenly, primarily from ventricular tachycardia to ventricular fibrillation [1]. Sympathetic nerve activity is increased in HF [2]. It is widely accepted that the cardiac response to catecholamines is mediated primarily by $\beta$ adrenoreceptors ( $\beta$-ARs). Arrhythmogenesis in HF is enhanced by $\beta$-adrenergic stimulation [3].

The human ether-a-go-go-related gene (hERG or KCNH2) [4] encodes the $\alpha$ subunit of the channel underlying $\mathrm{I}_{\mathrm{Kr}}$ [5], which is crucial for the repolarization of cardiac action potentials (AP). $\mathrm{I}_{\mathrm{Kr}}$ is modulated by catecholamines. There is increasing evidence that hERG $/ \mathrm{I}_{\mathrm{Kr}}$ channels are modulated by various $\mathrm{G}$ protein-coupled receptors including $\alpha$ - and $\beta$-ARs, which act through the intracellular signaling modulators cAMP, protein kinase A (PKA), and protein kinase $\mathrm{C}$ (PKC) $[6,7,8,9]$. Stimulation of $\beta$ AR by $10 \mu \mathrm{M}$ isoprenaline decreased $\mathrm{I}_{\mathrm{Kr}}$ tail currents in guinea pig ventricular myocytes [7]. Similarly, PKA-mediated phosphorylation of expressed hERG channels significantly decreased hERG currents [10]. However, recent studies have revealed that $\mathrm{I}_{\mathrm{Kr}}$ tail currents are enhanced by $100 \mathrm{nM}$ isoprenaline in canine ventricular myocytes [11]. It is well known that $\beta_{1}-\mathrm{AR}$ is downregulated and $\beta_{2}$-AR is relatively preserved in $\mathrm{HF}$. In addition, experimental studies have demonstrated that canine ventricular response to $\beta_{2}$-agonists is increased in tachypacing failure [12]. The responsiveness of cardiac $L$-type calcium current to $\beta_{2}$-AR stimulation is increased in rats with $\mathrm{HF}$ induced by ligation of the coronary artery [13]. However, the role and mechanism of $\beta_{2}$-AR activation in $\mathrm{I}_{\mathrm{Kr}}$ in $\mathrm{HF}$ have not been previously assessed. Accordingly, the present study was designed to examine the role and possible mechanisms of $\beta_{2}$-AR activation in $\mathrm{I}_{\mathrm{Kr}}$ in left ventricular $(\mathrm{LV})$ myocytes from HF guinea pigs using the whole cell patch clamp technique.

\section{Results}

Validity of the Guinea Pig Model

Following 12 weeks of thoracic aortic banding, the ejection fraction (EF) and fractional shortening (FS) of the heart of guinea 
pigs were significantly decreased; LV end-diastolic diameter, LV end-systolic diameter, the QT interval, and corrected QT interval were significantly increased while there were no changes in heart rate (Table 1). Cell capacitance of HF LV myocytes ( $\mathrm{n}=35$ cells; 20 animals) and control LV myocytes ( $\mathrm{n}=35$ cells; 16 animals) was $163 \pm 7$ and $121 \pm 3 \mathrm{pF}$, respectively $(\mathrm{P}<0.001)$. Cell capacitance was increased in HF LV myocytes. All guinea pigs with $\mathrm{HF}$ developed ascites and pleural effusion. Thus, the HF model of guinea pigs induced by pressure overload is valid.

\section{HF Reduces $I_{\mathrm{kr}}$ Tail Current Density}

$\mathrm{I}_{\mathrm{kr}}$ tail currents of guinea pig LV myocyte were completely abolished by the specific $\mathrm{I}_{\mathrm{kr}}$ blocker, dofetilide $(1 \mu \mathrm{m})$ (Figure 1A), indicating that $\mathrm{I}_{\mathrm{kr}}$ tail currents were measured free of contamination by other currents under the given experimental conditions. The amplitude of $\mathrm{I}_{\mathrm{Kr}}$ tail currents in HF myocytes was smaller than that of sham-operated controls (Figure 1B). Figure 1C shows the current-voltage $(\mathrm{I}-\mathrm{V})$ relationship of $\mathrm{I}_{\mathrm{Kr}}$ tail current density. The $\mathrm{I}_{\mathrm{Kr}}$ tail current density in HF myocytes was significantly lower than that in control myocytes, from $0 \mathrm{mV}$ to positive potentials (at $+40 \mathrm{mV}, 0.21 \pm 0.01 \mathrm{pA} / \mathrm{pF}, \mathrm{n}=33$, vs. $0.43 \pm 0.03 \mathrm{pA} / \mathrm{pF}, \mathrm{n}=24$; $\mathrm{p}<0.001)$.

\section{$\mathrm{I}_{\mathrm{kr}}$ Inhibition Induced by $\beta_{2}$-AR Stimulation in $\mathrm{HF}$ Ventricular Myocytes}

In control myocytes, the selective $\beta_{2}$-AR agonist fenoterol $(10 \mu \mathrm{M})$ decreased $\mathrm{I}_{\mathrm{kr}}$ tail currents by $17 \pm 5 \%(\mathrm{n}=6$, vs. control myocytes in the absence of fenoterol, $\mathrm{p}=0.11$; Figure $2 \mathrm{~A}$ and $2 \mathrm{C}$ ). In contrast, fenoterol $(10 \mu \mathrm{M})$ decreased $\mathrm{I}_{\mathrm{kr}}$ tail currents by $33 \pm 7 \%$ in HF myocytes $(\mathrm{n}=6$, vs. HF myocytes in the absence of fenoterol, $\mathrm{p}<0.05$; Figure $2 \mathrm{~B}$ and $2 \mathrm{C}$ ). The reduction of $\mathrm{I}_{\mathrm{Kr}}$ tail current occurred within 2-4 min and reached saturation about 10 min after addition of fenoterol $(10 \mu \mathrm{M})$ into the bath. After washout of fenoterol, $\mathrm{I}_{\mathrm{kr}}$ tail current reached $83.5 \pm 4.5 \%$ and $67.8 \pm 6.7 \%$ of the control and $\mathrm{HF}$ value, respectively. The inhibitory effect of fenoterol was almost not reversible (Figure 2C).

\section{Effects of $\beta_{1}$ - and $\beta_{2}$-AR Blockade on Fenoterol-induced Decrease in $\mathrm{I}_{\mathrm{kr}}$}

We used the selective $\beta_{2}$-AR antagonist ICI1 18551 to examine whether the $I_{\mathrm{Kr}}$ response to fenoterol was mediated through $\beta_{2^{-}}$ $\mathrm{AR}$ in $\mathrm{HF}$ myocytes. When $10 \mu \mathrm{M}$ ICI118551 was applied along with fenoterol, it almost totally prevented fenoterol-induced

Table 1. Echocardiographic and electrocardiographic data of control and heart failure guinea pigs.

\begin{tabular}{lll}
\hline Group & $\mathbf{C T L}(\mathbf{n}=\mathbf{1 0})$ & $\mathbf{H F}(\mathbf{n}=\mathbf{1 0})$ \\
\hline EF (\%) & $80.97 \pm 0.28$ & $67.88 \pm 2.66^{* *}$ \\
FS (\%) & $44.47 \pm 0.27$ & $34.01 \pm 1.95^{* *}$ \\
LVEDd (mm) & $6.25 \pm 0.91$ & $7.75 \pm 1.32^{*}$ \\
LVESd (mm) & $3.51 \pm 0.61$ & $5.28 \pm 0.48^{* *}$ \\
HR(beats/min) & $243 \pm 11$ & $260 \pm 12$ \\
QT(ms) & $142.44 \pm 5.73$ & $167.98 \pm 9.37^{*}$ \\
QT $(\mathrm{ms})$ & $284.43 \pm 10.76$ & $327.48 \pm 8.55^{*}$ \\
\hline
\end{tabular}

Values are mean $\pm \mathrm{SEM}$. Control $(\mathrm{CTL})$, sham-operated guinea pigs; $\mathrm{EF}$, ejection fraction; FS, fractional shortening; LVEDd, left ventricle end-diastolic diameter; LVESd, left ventricle end-systolic diameter; HR, heart rate; QT, interval; QTc, corrected QT interval; $n$, number of guinea pigs. ${ }^{*} p<0.05,{ }^{* *} p<0.01$ vs. CTL. doi:10.1371/journal.pone.0046186.t001 inhibition of $\mathrm{I}_{\mathrm{Kr}}$ (fenoterol alone, $33 \pm 7 \%$ decrease, $\mathrm{n}=6$;

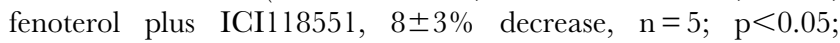
Figure $3 \mathrm{~A}$ and $3 \mathrm{C}$ ). However, in five $\mathrm{HF}$ myocytes, fenoterol decreased $\mathrm{I}_{\mathrm{Kr}}$ by $32 \pm 5 \%$ in the presence of CGP20712A, a selective $\beta_{1}-A R$ antagonist (Figure $3 \mathrm{~B}$ and $3 \mathrm{C}$ ). Under these conditions, the present results supported the role of the $\beta_{2}$-AR subtype in the modulation of $\mathrm{I}_{\mathrm{Kr}}$ in $\mathrm{HF}$ myocytes.

\section{$\beta$-AR mRNA and Protein Expression in HF}

Figure $4 \mathrm{~A}$ and $\mathrm{B}$ show that $\beta_{1}$-AR mRNA levels were reduced $52 \%$ in HF guinea pigs compared with controls $(\mathrm{n}=5, \mathrm{p}<0.05)$, whereas $\beta_{2}$-AR mRNA levels remained unchanged. $\beta_{1}$-AR protein showed a significant decline, as illustrated in Figure 4C. $\beta_{2}$-AR protein remained unchanged (Figure $4 \mathrm{D}$ ).

\section{$\mathrm{I}_{\mathrm{Kr}}$ Inhibition Induced by $\beta_{2}$-AR Stimulation Involves the CAMP/PKA Pathway}

It is known that the hERG $\mathrm{K}^{+}$channel can be modulated by cAMP and PKA. $\beta_{2}$-AR is coupled to the stimulatory $\mathrm{G}_{\mathrm{s}}$ protein, which leads to the activation of adenylyl cyclase and production of cAMP. To examine whether cAMP activation mediates the $I_{\mathrm{Kr}}$ response to $\beta_{2}$-AR stimulation, we investigated the effect of inhibitory cAMP analog Rp-cAMPS on the stimulatory action of fenoterol. As shown in Figure $5 \mathrm{~A}$ and $5 \mathrm{C}$, with intracellular application of Rp-cAMPS $(100 \mu \mathrm{M})$, fenoterol-induced $\mathrm{I}_{\mathrm{Kr}}$ decrease was almost fully prevented in $\mathrm{HF}$ myocytes (fenoterol alone, $33 \pm 7 \%$ decrease, $n=6$; Rp-cAMPS, $6 \pm 1 \%$ decrease, $\mathrm{n}=6 ; \mathrm{p}<0.05)$. These results suggest that $\mathrm{I}_{\mathrm{Kr}}$ inhibition induced by $\beta_{2}$-AR stimulation involves cAMP activation.

We further examined the effect of PKA inhibition on the inhibitory effects of fenoterol. As illustrated in Figure 5B and 5C, fenoterol-induced $\mathrm{I}_{\mathrm{kr}}$ decrease was largely abolished by pretreatment of HF myocytes with KT5720 (fenoterol alone, $33 \pm 7 \%$ decrease, $n=6$; fenoterol plus KT5720, 18 $\pm 4 \%$ decrease, $n=5$; $\mathrm{p}=0.051)$, supporting an involvement of PKA activation.

\section{Action Potential Duration (APD) is Prolonged by $\beta_{2}$-AR Stimulation in HF Ventricular Myoctyes}

Because action potential duration (APD) is dependent on the balance between depolarizing inward and repolarizing outward currents, an alteration in the amplitude of major repolarizing current such as $\mathrm{I}_{\mathrm{Kr}}$ would lead to substantial changes in the repolarization process. We therefore examined the effects of fenoterol on AP in LV myocytes. Figure $6 \mathrm{~A}$ and $6 \mathrm{~B}$ shows the superimposed traces of $\mathrm{AP}$ recorded before and during exposure to fenoterol $(10 \mu \mathrm{M})$ in control and HF myocytes. A summary of corresponding data is shown in Figure 6C. APD at $90 \%$ repolarization $\left(\mathrm{APD}_{90}\right)$ was significantly prolonged in $\mathrm{HF}$ myocytes compared with control $(315.1 \pm 8.1 \mathrm{~ms}, \mathrm{n}=8$, vs. $274.8 \pm 7.3 \mathrm{~ms}$, $\mathrm{n}=9 ; \mathrm{p}<0.01)$. Fenoterol caused significant prolongation of $\mathrm{APD}_{90}$ in $\mathrm{HF}$ myocytes $(9.5 \%, 344.6 \pm 6.5$ vs. $315.1 \pm 8.1 \mathrm{~ms}$, $\mathrm{n}=8 ; \mathrm{p}<0.05)$, whereas no significant prolongation of $\mathrm{APD}_{90}$ was observed in control myocytes $(3 \%, 283.6 \pm 7.7$ vs. $274.8 \pm 7.3 \mathrm{~ms}$, $\mathrm{n}=9$ ). Fenoterol did not influence the AP amplitude and resting potentials in control and $\mathrm{HF}$ ventricular myocytes.

\section{Discussion}

The present study demonstrates, for the first time, that increased response to $\beta_{2}$-AR stimulation produces an inhibitory effect on $\mathrm{I}_{\mathrm{Kr}}$ in ventricular myocytes of guinea pigs with descending aortic banding-induced heart failure, and this effect is induced by the activation of the cAMP/PKA pathway. 
A

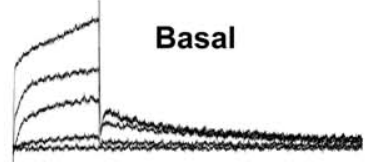

$+40 \mathrm{mV}$

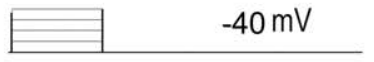

B

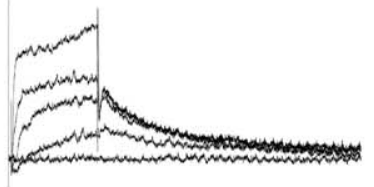

CTL
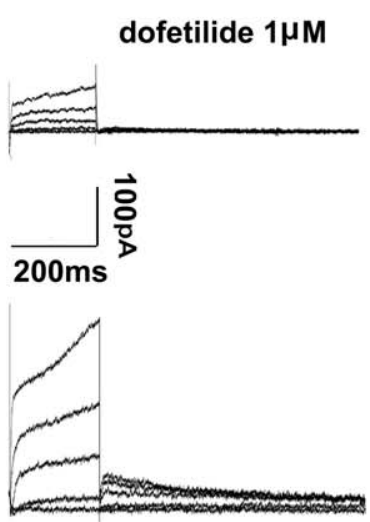

HF
C

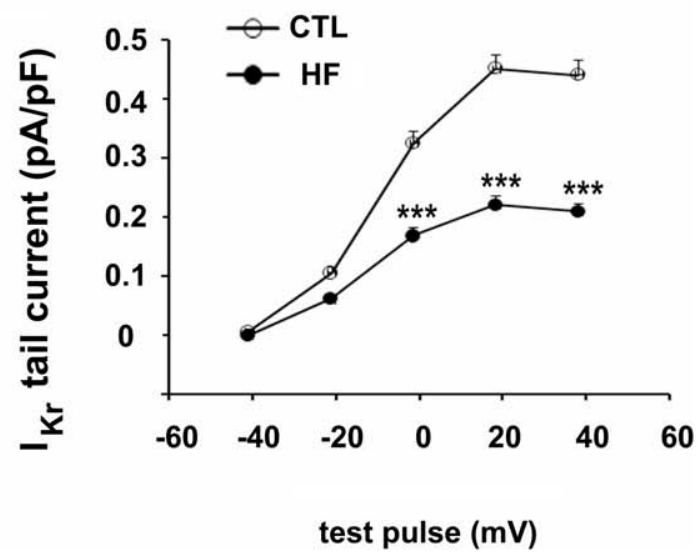

Figure 1. Changes of $I_{\mathbf{k r}}$ in heart failure (HF). (A) Recording of $I_{k r}$ tail current in a representative left ventricle (LV) myocyte before (left) and 10 min after exposure to dofetilide $(1 \mu \mathrm{M})$ (right). (B) Representative tail traces of $\mathrm{I}_{\mathrm{Kr}}$ in LV myocytes isolated from control (CTL, left) and HF guinea pigs (right). (C) The average current-voltage relationship of $I_{k r}$ plotted for control $(n=24$ cells, 8 hearts) and HF ( $n=33$ cells, 10 hearts) myocytes $\left({ }^{* * *} \mathrm{p}<0.001\right.$, HF vs. CTL). Test pulses were applied at various voltages from -40 to $+40 \mathrm{mV}$ (step width $20 \mathrm{mV}$, step duration $200 \mathrm{~ms}$ ) before returning to $-40 \mathrm{mV}$ for tail current recording.

doi:10.1371/journal.pone.0046186.g001

A

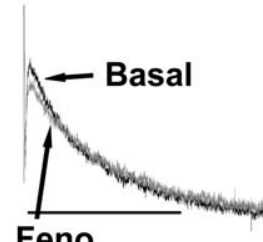

CTL
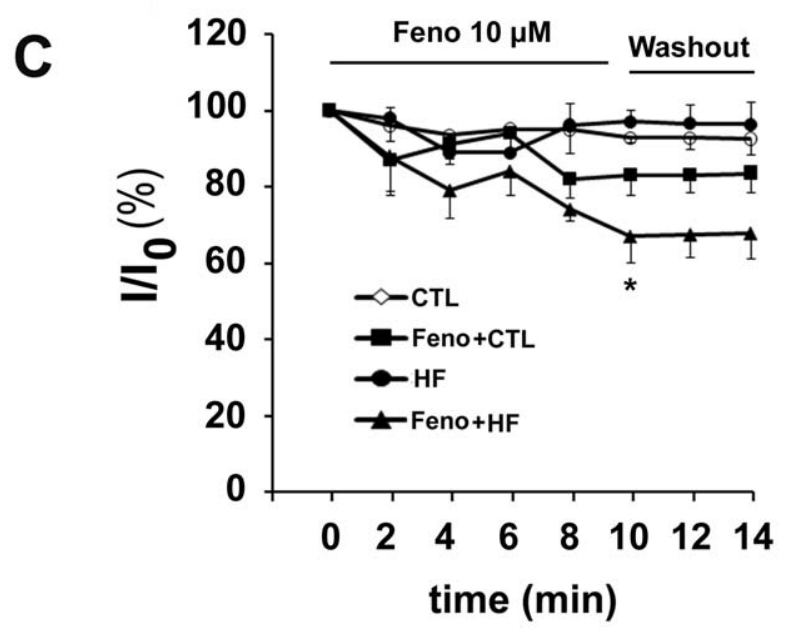

Figure 2. Effects of fenoterol (Feno) on $\mathbf{I}_{\mathbf{k r}}$. (A and $B$ ) Superimposed tail current traces of $\mathrm{I}_{\mathrm{kr}}$ recorded before and $10 \mathrm{~min}$ after application of $10 \mu \mathrm{M}$ Feno in a control myocyte and a heart failure (HF) myocyte, respectively. (C) Time-dependence of current reduction by the $\beta_{2}$-AR agonist fenoterol in control ( $\mathrm{n}=6$ cells, 3 hearts) and HF myocytes ( $n=6$ cells, 4 hearts, ${ }^{*} p<0.05$, Feno+HF vs. HF). Current amplitudes were measured at the voltage of $+40 \mathrm{mV}$. doi:10.1371/journal.pone.0046186.g002

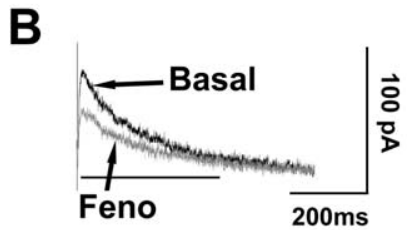

A

B

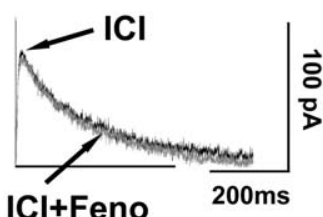

HF

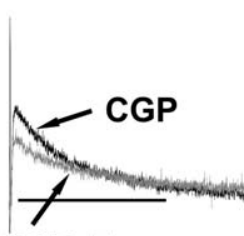

CGP+Feno

$\mathrm{HF}$

C

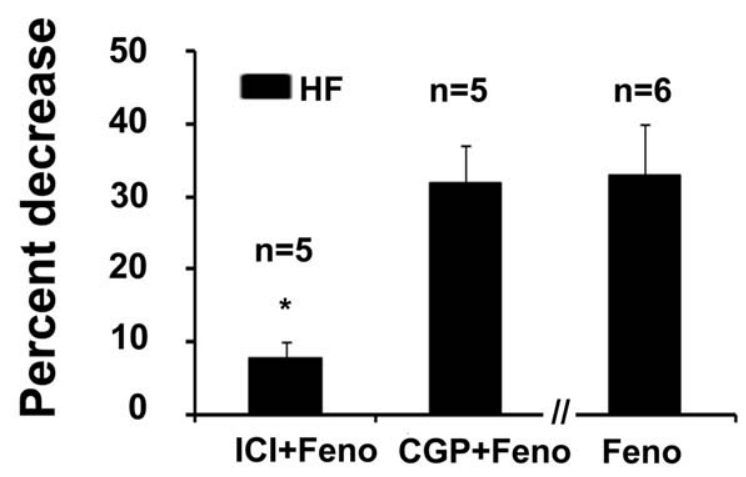

Figure 3. $\beta_{2}$-AR mediates the inhibition of $I_{k r}$ by fenoterol (Feno) in heart failure (HF) myocytes. (A and B) Superimposed tail current traces of $I_{\mathrm{kr}}$ recorded before and $10 \mathrm{~min}$ after application of $10 \mu \mathrm{M}$ fenoterol in the presence of the selective $\beta_{2}$-AR antagonist ICI118551 (ICl, $10 \mu \mathrm{M})$ and $\beta_{1}$-AR antagonist CGP20712A (CGP, $10 \mu \mathrm{M}$ ) in a HF myocyte, respectively. (C) Summarized data for percent decrease in the amplitude of $\mathrm{I}_{\mathrm{Kr}}$ tail current evoked by ICl plus fenoterol, CGP plus fenoterol, and fenoterol alone $\left(n=5\right.$ and 6 cells, 3 hearts, ${ }^{*} \mathrm{P}<0.05$, Feno $+\mathrm{ICl}$ versus Feno). Current amplitudes were measured at the voltage of $+40 \mathrm{mV}$.

doi:10.1371/journal.pone.0046186.g003 
A

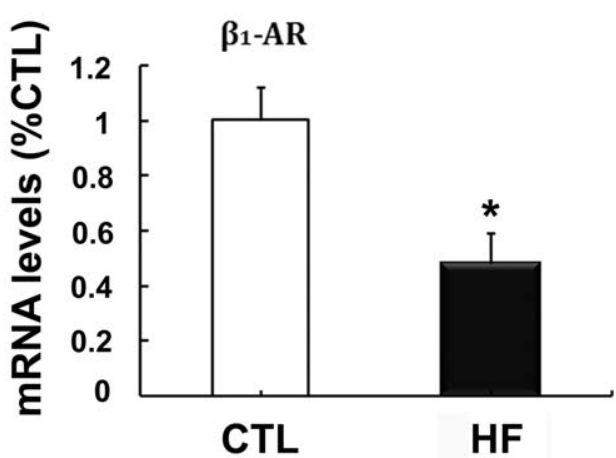

C
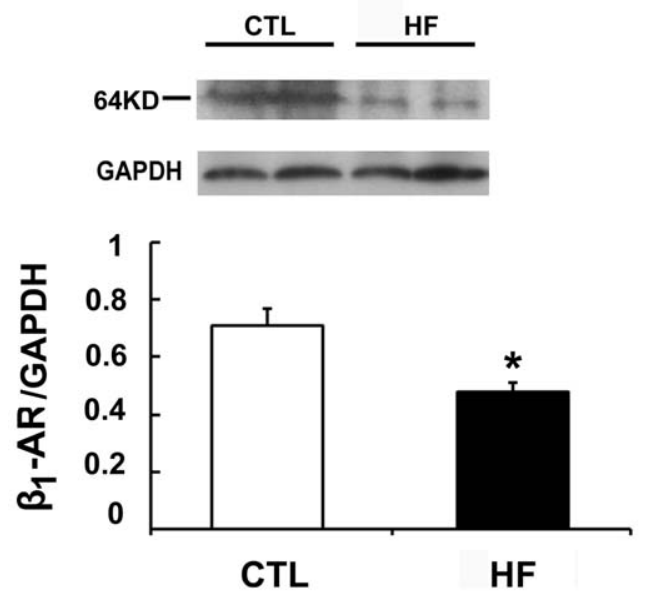

B

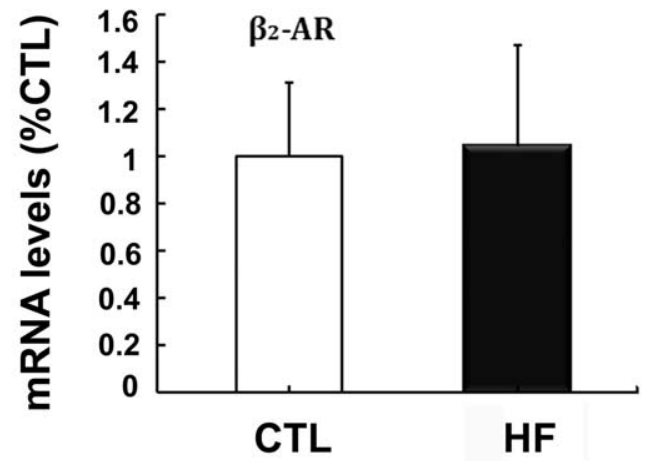

D
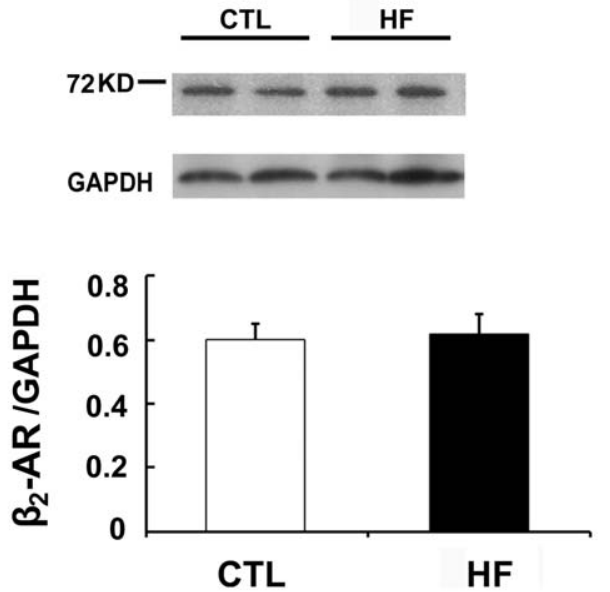

Figure 4. $\beta_{1}$-and $\beta_{2}$-AR mRNA and protein expression in heart failure (HF). (A) $\beta_{1}$-AR mRNA level ( $n=5$, ${ }^{*} p<0.05, H F$ vs.control, $C T L$ ). (B) $\beta_{2}$ AR mRNA level $(n=5)$. (C) Representative protein bands of $\beta_{1}$-AR in control and HF samples (upper); $\beta_{1}$-AR protein expression (bottom, $n=5$, ${ }^{*} \mathrm{p}<0.05$, HF vs. CTL). (D) Representative protein bands of $\beta_{2}-A R$ in control and HF samples (upper); $\beta_{2}$-AR protein expression (bottom). doi:10.1371/journal.pone.0046186.g004

\section{Inhibitory Effect of $\beta_{2}$-AR Activation on $\mathrm{I}_{\mathrm{Kr}}$ in $\mathrm{HF}$ Ventricular Myocytes}

The hERG channel (Kv1 1.1) underlies the rapid component of delayed rectifier potassium current $\left(\mathrm{I}_{\mathrm{kr}}\right)$ and is critical for the kinetics of cardiac AP repolarization $[5,14]$. There is increasing evidence that $h E R G / I_{\mathrm{Kr}}$ channels are modulated by various $G$ protein-coupled receptors including $\alpha$ - and $\beta$-ARs, acting through the intracellular signaling modulators cAMP, PKA, and PKC $[6,7,8,9,11]$. It has been increasingly recognized that $\beta_{1}$-and $\beta_{2^{-}}$ $\mathrm{AR}$ coexist in the heart. In large mammal hearts, $\beta_{2}$-AR may account for approximately $40 \%$ of $\beta$-AR in total. The reported ratio of $\beta_{1}-/ \beta_{2}-A R$ was $85 / 15$ in guinea pig hearts [15]. Consistent with previous observations [16], in our HF guinea pigs, $\beta_{1}-\mathrm{AR}$ was downregulated; however, $\beta_{2}$-AR was unaltered. The increase of $\beta_{2}$-AR density has been demonstrated in the $L V$ of dogs with pacing-induced HF [17]. It has been demonstrated that in diseased ventricles, $\beta_{2}-\mathrm{AR}$ stimulation exhibits a heightened response $[12,13]$. Our results demonstrate, for the first time, that the responsiveness of $I_{\mathrm{Kr}}$ to $\beta_{2}$-AR stimulation is enhanced in $\mathrm{HF}$ guinea pigs ventricular myocytes. The effect of selective $\beta_{2}$-AR agonist fenoterol $(10 \mu \mathrm{M})$ on $\mathrm{I}_{\mathrm{Kr}}$ was far less effective in control myocytes; whereas, $\mathrm{I}_{\mathrm{Kr}}$ was significantly inhibited by $10 \mu \mathrm{M}$ fenoterol in $\mathrm{HF}$ myocytes. The reduction of $\mathrm{I}_{\mathrm{Kr}}$ tail current occurred within 2-4 min and reached saturation about $10 \mathrm{~min}$ after addition of fenoterol into the bath. After washout of fenoterol, the inhibitory effect on $\mathrm{I}_{\mathrm{Kr}}$ tail current was almost irreversible. In order to identify the $\beta_{2}$-AR specific effect, we used salbutamol $(10 \mu \mathrm{M})$, another highly selective $\beta_{2}$-AR agonist, and achieved similar results (data not shown). Moreover, the inhibitory effect of fenoterol was almost completely abolished by $\beta_{2}$-AR antagonist, but not by the $\beta_{1}-\mathrm{AR}$ antagonist. Therefore, our findings indicate that the $\mathrm{I}_{\mathrm{Kr}}$ inhibition induced by fenoterol is due to $\beta_{2}$-AR activation.

Heart failure induced by pressure overload is a non-ischemic heart failure, which exhibits clinical and pathological features typical of hypertension-induced heart failure. Consistent with previous observations, myocytes from these hearts were enlarged. This model of heart failure is widely applied in the study of cardiac cellular electrophysiology. Sympathetic nervous system is activated in response to exercise and emotional stress, which results in increased levels of local and circulating catecholamines. Plasma norepinephrine levels of $\sim 3 \mu \mathrm{M}$ and peak exercise norepinephrine levels of $\sim 15 \mu \mathrm{M}$ have been detected in chronic $\mathrm{HF}$ in humans [18], giving our present findings utilizing $10 \mu \mathrm{M}$ fenoterol a clinical relevance. 
A

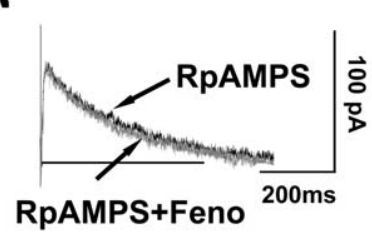

HF

C

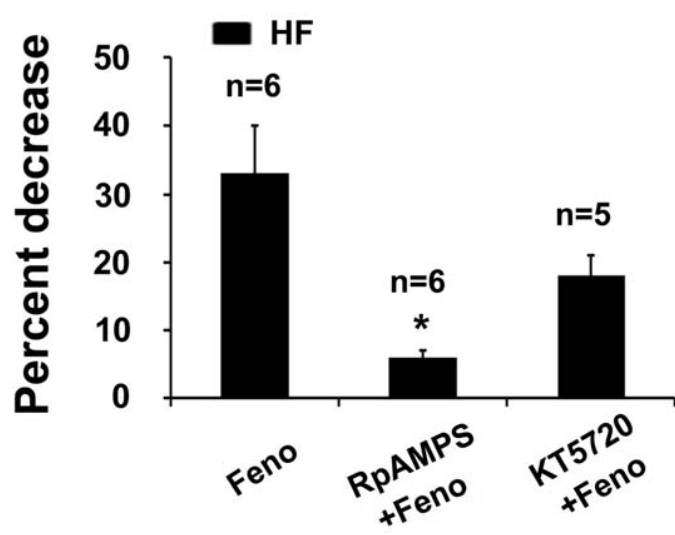

Figure 5. Effects of CAMP inhibition and PKA inhibition on $I_{k r}$ response to $\boldsymbol{\beta}_{\mathbf{2}}$-AR stimulation. (A) Superimposed tail current traces of $\mathrm{I}_{\mathrm{kr}}$ recorded before and $10 \mathrm{~min}$ after application of $10 \mu \mathrm{M}$ fenoterol (Feno) in the presence of RpCAMPS $(100 \mu \mathrm{M})$ in pipette solution in a heart failure (HF) myocyte. (B) Superimposed tail current traces of $\mathrm{I}_{\mathrm{kr}}$ recorded before and $10 \mathrm{~min}$ after application of $10 \mu \mathrm{M}$ Feno in the presence of PKA inhibitor, KT5720 $(2.5 \mu \mathrm{M})$ in a HF myocyte. (C) Summarized data for percent decrease in the amplitude of $\mathrm{I}_{\mathrm{Kr}}$ tail current evoked by Feno alone, RpCAMPS plus fenoterol, and KT5720 plus Feno in HF myocytes ( $n=6,6$, and 5 cells, 3 hearts, ${ }^{*} p<0.05$, RpCAMPS+ Feno vs. Feno). Current amplitudes were measured at the voltage of $+40 \mathrm{mV}$.

doi:10.1371/journal.pone.0046186.g005

cAMP/PKA Involvement in the Inhibitory Effect of $\beta_{2}$-AR Activation on $\mathrm{I}_{\mathrm{Kr}}$

Stimulation of different $G$ protein-coupled receptors, including $\alpha_{1}$ - and $\beta$-ARs, regulates $I_{K r}$ through intracellular messengers and provides a link between autonomic stimulation and cardiac repolarization [19]. Stimulation of $\beta_{2}$-AR in the heart has classically been known to result in $\mathrm{G}_{\mathrm{s}}$-mediated stimulation of adenylyl cyclase (AC), which leads to increased cellular cAMP, thus activating PKA [20]. It has been demonstrated in the Xenopus laevis oocyte expression system that PKA can reduce hERG currents via direct phosphorylation of all four putative PKA consensus sites [10]. In the present study, we demonstrated that fenoterol-induced inhibition of $\mathrm{I}_{\mathrm{Kr}}$ was fully prevented by intracellular application of Rp-cAMPS, an inhibitory cAMP analog, suggesting that this effect may be mediated through a cAMP-dependent mechanism in HF ventricular myocytes. Furthermore, fenoterol-induced inhibition of $\mathrm{I}_{\mathrm{Kr}}$ was partly attenuated by PKA inhibitor, implicating the involvement of PKA activation. The dual regulation of $\mathrm{I}_{\mathrm{Kr}}$ by cAMP and PKA phosphorylation has been previously demonstrated [21]. hERG current may be decreased by cAMP-dependent activation of PKA; however, a putative direct binding of cAMP to the channel causes opposite effects. The net effect of dual hERG current regulation by
PKA and cAMP is current reduction. A recent study has shown that $\beta_{2}$-AR redistribution in HF can change cAMP compartmentation [22]. Our results do not exclude the possibility of direct binding of cAMP to the channel.

Cardiac $\beta_{2}-A R$ can couple with both $G_{\mathrm{s}}$ and $G_{i}$ proteins. The complexity of the $\beta_{2}$-AR signaling pathway, including functional compartmentalization of signaling mediated by $G_{i}$, phosphatidylinositol 3-kinase, and mitogen-activated protein kinases (MAPKs), has been documented [20,23]. Recently, Li et al. has reported that one or more A-kinase anchoring proteins (AKAPs) targets PKA to HERG channels and may contribute to the acute regulation of $\mathrm{I}_{\mathrm{Kr}}$ by cAMP [24]. AKAPs are a structurally diverse group of proteins that lack primary structure sequence homology but share the function of localizing PKA to subcellular structures, substrates, and oftentimes with other members of the signaling pathway [25]. $\beta$-adrenergic signaling is maintained by the localization of PKA and phosphodiesterases to subcellular microdomains. In addition, in the rat brain, $\beta_{2}$-ARs are found to be associated directly with Cav1.2 in a macromolecular signaling complex [26]. Indeed, the precise mechanism for $\beta_{2}$-adrenergic stimulation-induced inhibition of $\mathrm{I}_{\mathrm{Kr}}$ for $\mathrm{HF}$ myocytes remains to be further elucidated. For example, it remains unclear whether $G_{i}$ pathway or a $\beta_{2}$-ARmacromolecular signaling complex mediates the inhibition of $\mathrm{I}_{\mathrm{Kr}}$ via $\beta_{2}$-AR in $\mathrm{HF}$ ventricular myocytes.

\section{APD Prolongation by $\beta_{2}$-AR Stimulation}

One of the most characteristic electrophysiological remodeling in failing heart is APD prolongation, which is believed to mainly result from the downregulation of repolarizing outward potassium currents, including $\mathrm{I}_{\text {to }}$ (transient outward $\mathrm{K}^{+}$current $), \mathrm{I}_{\mathrm{Ks}}$ and $\mathrm{I}_{\mathrm{Kr}}$ in heart failure $[27,28]$. In the present study, we found that QT interval was increased in failing guinea pigs and APD was prolonged in failing ventricular myocytes. Fenoterol caused significant prolongation of $\mathrm{APD}_{90}$ in failing ventricular myocytes, whereas no significant prolongation of $\mathrm{APD}_{90}$ was observed in control myocytes. The present study provides evidence that fenoterol-induced inhibition of $\mathrm{I}_{\mathrm{Kr}}$ may result in delay in cardiac repolarization via stimulation of $\beta_{2}$ - $\mathrm{AR}$ in failing ventricular myocytes. Because the $\mathrm{I}_{\mathrm{Kr}}$ is crucial for the repolarization of cardiac AP, inhibition of $I_{K r}$ induced by stimulation of $\beta_{2}-A R$ in failing ventricular myocytes may in part contribute to the delay in cardiac repolarization.Ventricular myocytes from the guinea pig heart possess a time- and voltage-independent $\mathrm{Cl}^{-}$current induced by $\beta$-adrenoceptor activation $[29,30]$. Activation of this current will result in outward current during the plateau phase of AP, shortening APD [31]. One limitation of the present study is that the AP experiments were performed without considering cAMP modulated $\mathrm{Cl}^{-}$current. Therefore, the effect of fenoterol on cardiac repolarization should be studied without ignoring other currents in the future.

In conclusion, the inhibitory effect of $\mathrm{I}_{\mathrm{Kr}}$ induced by $\beta_{2}$-AR stimulation is increased in HF. The effect is likely to be mediated through a cAMP/PKA pathway mechanism in $\mathrm{HF}$ ventricular myocytes. This regulatory pathway of the $\beta_{2}$-adrenergic system on $\mathrm{I}_{\mathrm{kr}}$ current provides a possible relationship between stress and lifethreatening arrhythmias in HF.

\section{Materials and Methods}

All experiments were performed in accordance with animal care protocols approved by the Nanjing Medical University Institutional Animal Care and Use Committee. 
A

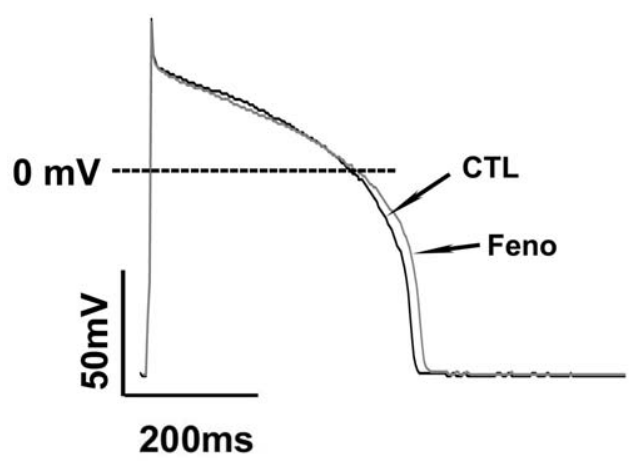

B

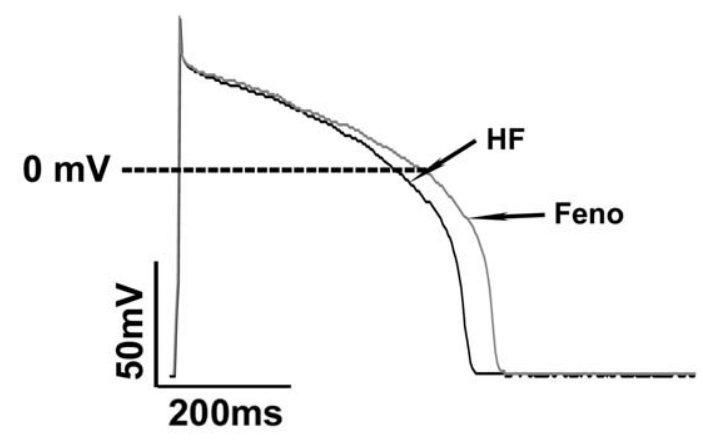

C

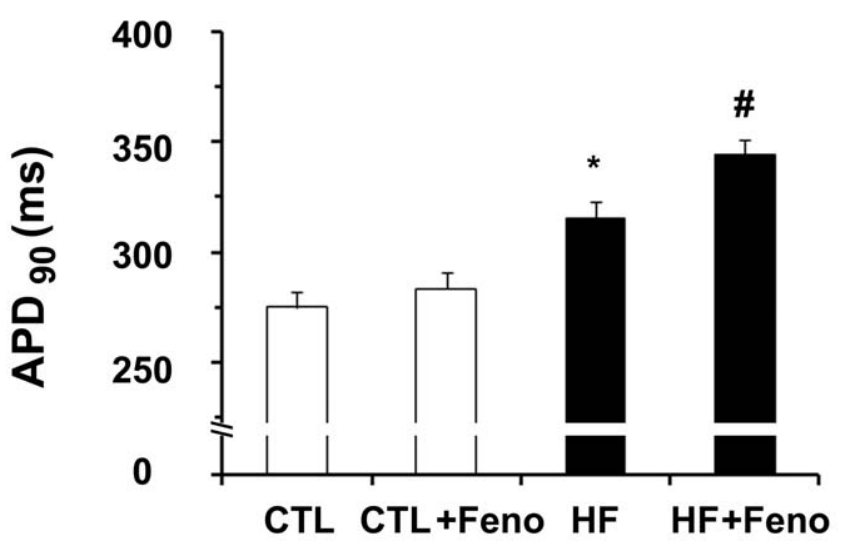

Figure 6. Effects of fenoterol (Feno) on action potential duration (APD). (A and B) Superimposed action potentials recorded before and $10 \mathrm{~min}$ after exposure to $10 \mu \mathrm{M}$ Feno in a control and a heart failure (HF) myoctye of guinea pigs, respectively. (C) Summarized data for changes in APD at $90 \%$ of repolarization $\left(\mathrm{APD}_{90}\right.$ ) by exposure to Feno in control ( $n=8$ cells, 3 hearts) and HF myocytes $\left(n=9\right.$ cells, 4 hearts, ${ }^{*} p<0.01$, HF vs. control; ${ }^{\#} \mathrm{p}<0.05$, HF +fenoterol vs. HF).

doi:10.1371/journal.pone.0046186.g006

\section{Heart Failure Model in Guinea Pigs}

Heart failure was induced in adult male guinea pigs (250 to $300 \mathrm{~g})$ by subtotal descending thoracic aortic banding. After sodium pentobarbital anesthesia (25 mg/ kg, i.p.), the descending thoracic aorta was exposed sterilely through an incision in the left third intercostal space. A uniform degree of constriction around the descending thoracic aorta was produced by tightening a 2-0 surgical silk ligature around an 18-gauge needle. The needle was then withdrawn from the ligature, and the chest incision was closed. Sham animals underwent the same operation, with the exception that the aorta was not banded. Sham-operated animals were used as control. Aortic-banded animals and sham animals were housed and fed under identical conditions and were used 12 weeks after surgery. To monitor the progress of HF during the observation period, two-dimensional echocardiography (Sonos 5500, Hewlett Packard, Andover, MA, USA) was carried out periodically. ECGs and two-dimensional echocardiography were obtained under anesthesia (ketamine hydrochloride; $30 \mathrm{mg} / \mathrm{kg}$, i.p.). The QTc was calculated by Bazett's formula where $\mathrm{QTc}_{\mathrm{T}} \mathrm{QT} / \sqrt{\mathrm{RR}}$. Following 12 weeks of aortic banding, guinea pigs showed signs of $\mathrm{HF}$, including ventricular dilation, decreased ejection fraction (EF) and fractional shortening (FS), ascites, and pleural effusions.

\section{Myocyte Isolation and Electrophysiological Recordings}

Single left ventricular (LV) myocytes were enzymatically dissociated from the heart of guinea-pigs (550-600 g) as described previously [6] with minor modification. Cardiomyocytes were transferred to a recording chamber that was continuously perfused with a bath solution. Pipettes had resistances of 3-6 M $\Omega$ after filling with the pipette solution. Following seal formation, access developed within 2-5 min and series resistance was compensated up to $80 \%$. Whole-cell patch-clamp recordings were performed with an EPC-9 amplifier (HEKA, Germany). Flow rate through the chamber was maintained at $2-3 \mathrm{ml} / \mathrm{min}$. $\mathrm{I}_{\mathrm{kr}}$ was determined using the following test pulse protocol: after a holding potential of $-40 \mathrm{mV}$, test pulses were applied at various voltages from -40 to $+40 \mathrm{mV}$ (step width $20 \mathrm{mV}$, step duration $200 \mathrm{~ms}$ ) prior to returning to $-40 \mathrm{mV}$ for tail current recording $[6,7]$. $\mathrm{I}_{\mathrm{Kr}}$ current was recorded at $37 \pm 0.5^{\circ} \mathrm{C}$. Substance effects were investigated on tail currents after the test pulse was applied at $+40 \mathrm{mV}$. Measurements were repeated every two min.

For AP recording, extracellular solution (in $\mathrm{mmol} / \mathrm{L}$ ) contained $\mathrm{NaCl} 137, \mathrm{KCl} 5.4, \mathrm{MgCl}_{2}$ 1.0, $\mathrm{CaCl}_{2}$ 1.8, glucose 10 , and HEPES 10; $\mathrm{pH}$ was adjusted to 7.4 with $\mathrm{NaOH}$. Pipette solution (in $\mathrm{mmol} / \mathrm{L}$ ) contained potassium aspartate $120, \mathrm{KCl} 20, \mathrm{MgCl}_{2}$ 2.0, HEPES 10, EGTA 10, $\mathrm{Na}_{2}$ ATP 10; $\mathrm{pH}$ was adjusted to 7.2 with $\mathrm{KOH}$. APs were evoked using whole-cell current-clamp mode by suprathreshold current pulse of $5 \mathrm{~ms}$ duration at the 
Table 2. Gene-specific primer sequences used for real-time PCR analysis in this study.

\begin{tabular}{llll}
\hline & & & \\
\hline Gene & $\begin{array}{l}\text { Forward primer } \\
\text { sequence }\end{array}$ & $\begin{array}{l}\text { Reverse primer } \\
\text { sequence }\end{array}$ & GenBank \\
\hline$A D R B 1$ & TCTATGTGCCCCTGTGCAT & GTGAACACGCCCATGATGAT & EU332753.1 \\
ADRB2 & CATCGTCAACATTGTGCACG & TGCCCCTGGTGACAAACAT & AJ459814.1 \\
GAPDH & ACCACAGTCCATGCCATCAC & TCCACCACCCTGTTGCTGTA & \\
\hline
\end{tabular}

$A D R B 1$ and $A D R B 2$ refer to $\beta_{1}-A R$ and $\beta_{2}-A R$

doi:10.1371/journal.pone.0046186.t002

frequency of $1 \mathrm{~Hz}$. APD was measured at $90 \%$ repolarization (APD90). APs were generated with the same amplifier and recorded at $37 \pm 0.5^{\circ} \mathrm{C}$.

\section{Solutions and Drugs}

Preparation of the solution was performed as described previously by Wang et al. [6]. Calcium currents were blocked by the addition of $10 \mu \mathrm{M}$ nifedipine in the bath solution, and $10 \mu \mathrm{M}$ chromanol was used to block $\mathrm{I}_{\mathrm{ks}}$. $\mathrm{Na}_{2}$-ATP, EGTA, creatine phosphate, L-glutamic acid, HEPES, taurine, bovine serum albumin (BSA), nifedipine, isoproterenol, xamoterol, fenoterol, CGP20712A, ICI118551, and Rp-cAMPS were purchased from Sigma (St. Louis, MO), collagenase II from Invitrogen (Carlsbad, CA), and KT5720 from Merck KGaA (Darmstadt, Germany). Dofetilide, a specific blocker of $\mathrm{I}_{\mathrm{kr}}$ or hERG, was kindly provided by Pfizer Inc (NY, USA). All other reagents were obtained from Amresco (OH, USA).

For stock solutions, chromanol and KT5720 were dissolved in dimethyl sulfoxide (DMSO) at a final concentration of $1 \mathrm{mM}$ and stored at $-20^{\circ} \mathrm{C}$ until use. Final concentration of DMSO was less than $0.5 \%$ in the bath, which exerted no effect on the currents measured.

\section{Real Time RT-PCR Analysis}

RNA was extracted from $100 \mathrm{mg}$ of LV tissue using the Trizol reagent (Invitrogen) according to the manufacturer's protocol. RNA concentration was determined spectrophotometrically. Reverse transcription of $2 \mu \mathrm{g}$ RNA was performed in a $20-\mu \mathrm{l}$ reaction mixture using an RT kit (Takara Biotech). The GAPDH housekeeping gene was used as a reference for loading control. The primers for genes examined are shown in Table 2. Optimized PCR cycle parameters included $2 \mathrm{~min}$ at $95^{\circ} \mathrm{C}, 10 \mathrm{sec}$ at $95^{\circ} \mathrm{C}$ followed by $10 \mathrm{sec}$ at $95^{\circ} \mathrm{C}, 10 \mathrm{sec}$ at $57^{\circ} \mathrm{C}$ or $55^{\circ} \mathrm{C}$, and $45 \mathrm{sec}$ at $72^{\circ} \mathrm{C}$ for 40 cycles. Standard curves were determined for PCR efficiency. Quantitative real-time (RT) polymerase chain reaction PCR) was performed using the Applied Biosystems 7500 Real-time

\section{References}

1. Lloyd-Jones D, Adams RJ, Brown TM, Carnethon M, Dai S, et al. (2010) Heart disease and stroke statistics-2010 update: a report from the American Heart Association. Circulation 121: e46-e215.

2. Floras JS (2009) Sympathetic nervous system activation in human heart failure: clinical implications of an updated model. J Am Coll Cardiol 54: 375-385.

3. Pogwizd SM, Schlotthauer K, Li L, Yuan W, Bers DM (2001) Arrhythmogenesis and contractile dysfunction in heart failure: Roles of sodium-calcium exchange, inward rectifier potassium current, and residual beta-adrenergic responsiveness. Circ Res 88: 1159-1167.

4. Warmke JW, Ganetzky B (1994) A family of potassium channel genes related to eag in Drosophila and mammals. Proc Natl Acad Sci U S A 91: 3438-3442.

5. Sanguinetti MC, Jiang C, Curran ME, Keating MT (1995) A mechanistic link between an inherited and an acquired cardiac arrhythmia: HERG encodes the IKr potassium channel. Cell 81: 299-307.

6. Wang S, Xu DJ, Cai JB, Huang YZ, Zou JG, et al. (2009) Rapid component $\mathrm{I}(\mathrm{Kr})$ of cardiac delayed rectifier potassium currents in guinea-pig is inhibited by
PCR System (Applied Biosystems, Foster City, CA, USA) with SYBR Green I (Invitrogen). Relative mRNA expression was determined using the $2^{-\triangle \mathrm{Ct}}$ method.

\section{Western Blot Analysis}

Membrane fractions were prepared as previously described [32]. Protein samples were separated by $10 \%$ SDS-PAGE. The separated proteins were transferred by electrophoresis to PVDF membranes. Membranes were blocked for two h with Tris-Tween buffered saline (TTBS) solution containing 5\% nonfat dried milk and incubated overnight with primary antibody against $\beta_{1}$-AR and $\beta_{2}$-AR (both from Santa Cruz Biotechnology, Santa Cruz, CA). After washing, blots were incubated for one $h$ with appropriate peroxidase-conjugated goat anti-rabbit IgG secondary antibody (Santa Cruz Biotechnology). Staining was determined with chemiluminescence and quantified using image acquisition and analysis software. All data were expressed relative to GAPDH staining for the same samples on the same gels.

\section{Data Analysis}

The data were acquired using Pulse +Pulsefit V 8.53 and were expressed as mean \pm SEM. Western blot band intensities were expressed after background subtraction as optical density units (ODUs) normalized against GAPDH signal intensity for the same sample. Data comparisons were made using Student's $t$-test (paired or unpaired). Differences were considered statistically significant if $\mathrm{p}<0.05$.

\section{Acknowledgments}

We would like to thank Dr. Cui Bo for his prootreading of this thesis.

\section{Author Contributions}

Conceived and designed the experiments: HW DX KC JZ. Performed the experiments: HW YC HZ SW XZ. Analyzed the data: HW. Wrote the paper: HW JZ.

alpha(1)-adrenoreceptor activation via protein kinase A and protein kinase Cdependent pathways. Eur J Pharmacol 608: 1-6.

7. Karle CA, Zitron E, Zhang W, Kathofer S, Schoels W, et al. (2002) Rapid component $\mathrm{I}(\mathrm{Kr})$ of the guinea-pig cardiac delayed rectifier $\mathrm{K}(+)$ current is inhibited by beta(1)-adrenoreceptor activation, via cAMP/protein kinase Adependent pathways. Cardiovasc Res 53: 355-362.

8. Thomas D, Kiehn J, Katus HA, Karle CA (2004) Adrenergic regulation of the rapid component of the cardiac delayed rectifier potassium current, $\mathrm{I}(\mathrm{Kr})$, and the underlying hERG ion channel. Basic Res Cardiol 99: 279-287.

9. Zankov DP, Yoshida H, Tsuji K, Toyoda F, Ding WG, et al. (2009) Adrenergic regulation of the rapid component of delayed rectifier $\mathrm{K}+$ current: implications for arrhythmogenesis in LQT2 patients. Heart Rhythm 6: 1038-1046.

10. Thomas D, Zhang W, Karle CA, Kathofer S, Schols W, et al. (1999) Deletion of protein kinase A phosphorylation sites in the HERG potassium channel inhibits activation shift by protein kinase A. J Biol Chem 274: 27457-27462. 
11. Harmati G, Banyasz T, Barandi L, Szentandrassy N, Horvath B, et al. (2011) Effects of beta-adrenoceptor stimulation on delayed rectifier $\mathrm{K}(+)$ currents in canine ventricular cardiomyocytes. Br J Pharmacol 162: 890-896.

12. Altschuld RA, Starling RC, Hamlin RL, Billman GE, Hensley J, et al. (1995) Response of failing canine and human heart cells to beta 2-adrenergic stimulation. Circulation 92: 1612-1618.

13. Zhang ZS, Cheng HJ, Ukai T, Tachibana H, Cheng CP (2001) Enhanced cardiac L-type calcium current response to beta2-adrenergic stimulation in heart failure. J Pharmacol Exp Ther 298: 188-196.

14. Tamargo J, Caballero R, Gomez R, Valenzuela C, Delpon E (2004) Pharmacology of cardiac potassium channels. Cardiovasc Res 62: 9-33.

15. Voss HP, Shukrula S, Wu TS, Donnell D, Bast A (1994) A functional beta-2 adrenoceptor-mediated chronotropic response in isolated guinea pig heart tissue: selectivity of the potent beta-2 adrenoceptor agonist TA 2005. J Pharmacol Exp Ther 271: 386-389.

16. Bristow MR, Ginsburg R, Umans V, Fowler M, Minobe W, et al. (1986) Beta 1and beta 2-adrenergic-receptor subpopulations in nonfailing and failing human ventricular myocardium: coupling of both receptor subtypes to muscle contraction and selective beta 1-receptor down-regulation in heart failure. Circ Res 59: 297-309.

17. Kiuchi K, Shannon RP, Komamura K, Cohen DJ, Bianchi C, et al. (1993) Myocardial beta-adrenergic receptor function during the development of pacing-induced heart failure. J Clin Invest 91: 907-914.

18. Vittorio TJ, Zolty R, Kasper ME, Khandwalla RM, Hirsh DS, et al. (2008) Differential effects of carvedilol and metoprolol succinate on plasma norepinephrine release and peak exercise heart rate in subjects with chronic heart failure. J Cardiovasc Pharmacol Ther 13: 51-57.

19. Thomas D, Karle CA, Kiehn J (2006) The cardiac hERG/IKr potassium channel as pharmacological target: structure, function, regulation, and clinical applications. Curr Pharm Des 12: 2271-2283.

20. Xiang Y, Kobilka BK (2003) Myocyte adrenoceptor signaling pathways. Science 300: $1530-1532$
21. Cui J, Melman Y, Palma E, Fishman GI, McDonald TV (2000) Cyclic AMP regulates the HERG $\mathrm{K}(+)$ channel by dual pathways. Curr Biol 10: 671-674.

22. Nikolaev VO, Moshkov A, Lyon AR, Miragoli M, Novak P, et al. (2010) Beta2adrenergic receptor redistribution in heart failure changes cAMP compartmentation. Science 327: 1653-1657.

23. Steinberg SF (2004) beta(2)-Adrenergic receptor signaling complexes in cardiomyocyte caveolae/lipid rafts. J Mol Cell Cardiol 37: 407-415.

24. Li Y, Sroubek J, Krishnan Y, McDonald TV (2008) A-kinase anchoring protein targeting of protein kinase A and regulation of HERG channels. J Membr Biol 223: $107-116$

25. Smith FD, Langeberg LK, Scott JD (2006) The where's and when's of kinase anchoring. Trends Biochem Sci 31: 316-323.

26. Davare MA, Avdonin V, Hall DD, Peden EM, Burette A, et al. (2001) A beta2 adrenergic receptor signaling complex assembled with the $\mathrm{Ca} 2+$ channel Cav1.2. Science 293: 98-101.

27. Nattel S, Maguy A, Le Bouter S, Yeh YH (2007) Arrhythmogenic ion-channel remodeling in the heart: heart failure, myocardial infarction, and atrial fibrillation. Physiol Rev 87: 425-456.

28. Tomaselli GF, Marban E (1999) Electrophysiological remodeling in hypertrophy and heart failure. Cardiovasc Res 42: 270-283.

29. Pelzer S, You Y, Shuba YM, Pelzer DJ (1997) Beta-adrenoceptor-coupled Gs protein facilitates the activation of cAMP-dependent cardiac Cl- current. Am J Physiol 273: H2539-2548.

30. James AF, Tominaga T, Okada Y, Tominaga M (1996) Distribution of cAMPactivated chloride current and CFTR mRNA in the guinea pig heart. Circ Res 79: 201-207.

31. Duan D (2009) Phenomics of cardiac chloride channels: the systematic study of chloride channel function in the heart. J Physiol 587: 2163-2177.

32. Zicha S, Moss I, Allen B, Varro A, Papp J, et al. (2003) Molecular basis of species-specific expression of repolarizing $\mathrm{K}+$ currents in the heart. Am J Physiol Heart Circ Physiol 285: H1641-1649. 